\title{
IDENTIFIKASI STANDARISASI LABORATORIUM IPA di SALAH SATU MTS JEMBER
}

\author{
Neny Ismiyanti*, Riva Windasari*, Andika M. S*, Vivin H. M*, \\ Abdul Aziz*
}

*Program Studi Tadris IPA Institut Agama Islam Negeri Jember, Jember, Indonesia

Corresponding Author: nenyismiyanti@gmail.com

DOI: $10.35719 /$ vektor.v2i1.24

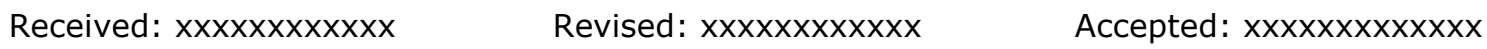

\begin{abstract}
Abstrak. Laboratorium sekolah yang baik harus memenuhi kelengkapan peralatan dan memperhatikan fasilitas penunjang sebagaimana yang ditetapkan oleh Permendiknas No. 24 Tahun 2007 tentang standarisasi laboratorium. Tujuan penelitian ini adalah untuk mengidentifikasi kelayakan dan optimalisasi laboratorium IPA yang terdapat di salah satu MTs yang ada di Kabupaten Jember. Penelitiaan ini berjenis peneltian deskriptif kualitatif. Sumber data yang digunakan berasal dari hasil wawancara. Sumber data primer adalah salah satu guru yang ada di MTs $X$ dan sumber data sekunder berasal dari berbagai artikel jurnal nasional. Teknik pengumpulan data menggunakan teknik wawancara bebas terpimpin. Hasil wawancara menginformasikan bahwa kegiatan praktikum yang dilaksanakan di salah satu sekolah MTs Jember masih belum terlaksana dengan baik. Peralatan yang terdapat di laboratorium MTs $X$ bisa dikatakan lengkap, termasuk ketersediaan KIT fisika. Dari hasil data yang diperolah dapat disimpulkan bahwa laboratorium yang terdapat disekolah tersebut kurang dioptimalkan dengan baik karena beberapa hal seperti guru yang mengajar di salah satu MTs $X$ bukan berasal dari background bidang studi IPA, kemudian sulitnya mendapatkan perizinan dari pihak yayasan untuk menggunakan laboratorium karena takut alat-alat laboratorium menjadi rusak.
\end{abstract}

Kata Kunci : Laboratorium, Pembelajaran IPA, Praktikum.

Abstract. A good school laboratory must meet the completeness of equipment and pay attention
to supporting facilities as stipulated by Permendiknas No. 24 of 2007 concerning laboratory
standardization. The purpose of this study was to identify the feasibility and optimization of the
science laboratory in one of the MTs in Jember Regency. This research is a qualitative descriptive
research. The source of the data used comes from the results of interviews. The primary data
source is one of the teachers in MTs $X$ and the secondary data sources are from various national
journal articles. Data collection techniques using guided free interview techniques. The results of
the interview informed that the practicum activities carried out in one of the MTs Jember schools
were still not carried out properly. The equipment in the MTs $X$ laboratory can be said to be
complete, including the availability of a physics KIT. From the results of the data obtained, it can be
concluded that the laboratory in the school is not optimized properly because several things, such
as the teacher who teaches at one MTs $X$ is not from a science background, then it is difficult to get 
permission from the foundation to use the laboratory for fear of tools. -Laboratory equipment is damaged.

Keywords: Laboratory, Science Learning, Practicum.

\section{PENDAHULUAN}

Pembelajaran IPA bukan hanya sebatas pengetahuan tentang suatu teori, konsepkonsep konkret, fakta atau prinsip-prinsip saja melainkan pembelajaran yang juga perlu menekankan adanya pengalaman langsung kepada siswa. Proses pembelajaran IPA akan lebih bermakna apabila dikaitkan dengan lingkungannya. Peserta didik seringkali mengalami kesulitan belajar pada pembelajaran IPA, apalagi jika berkaitan dengan materi-materi abstrak yang memerlukan pemahaman lebih. Pembelajaran IPA hendaknya menekankan pada pemberian pengalaman langsung untuk mengembangkan kompetensi menjelajahi dan memahami alam secara ilmiah (Subiantoro, 2014). Hal ini dapat membantu siswa untuk mendapatkan pemahaman yang lebih bermakna tentang alam yang ada disekitarnya.

Kegiatan pemberian pengalaman langsung kepada siswa dapat diimplementasikan dalam kegiatan praktikum. Kegiatan praktikum memiliki peranan penting dalam proses pencapaian tujuan pembelajaran IPA. Aktivitas praktikum ini dapat menumbuhkan keterampilan proses sains siswa, mengembangkan keterampilan dasar bereksperimen, memperoleh fakta dari sebuah konsep dan mengembangkan sikap ilmiah (Murti et al., 2014). Pelaksanaan kegiatan praktikum biasanya dilakukan diruang yang berbeda dengan ruang kelas. Praktikum dilaksanakan di laboratorium dengan ruangan yang sudah didesain secara khusus.

Laboratorium adalah tempat penelitian ilmiah, pengukuran, eksperimen, ataupun pelatihan ilmiah. Keberadaan laboratorium merupakan suatu keharusan di tengah pendidikan sains modern. Tersedianya alat dan bahan praktikum diperlukan untuk tercapainya pembelajaran IPA yang maksimal. Pengelolaan laboratorium akan lebih baik apabila dilakukan sebelum laboratorium digunakan sebagai sumber belajar oleh peserta didik. Dalam melakukan pengelolaan laboratorium sangat diperlukan untuk memenuhi kriteria perencanaan, pengorganisasian, pelaksanaan, pengawasan dan evaluasi.

Penelitian yang dilakukan oleh Adilah, dkk (2021) menyatakan kendala yang didapati dalam pelaksanaan praktikum, antara lain banyaknya peralatan yang rusak, bahan yang kadaluwarsa, ada alat yang tersedia tetapi tidak digunakan sebagaimana mestinya, dan juga tidak ada jadwal khusus terkait pelaksanaan praktikum (Adilah et al., 2021). Pemanfaatan sarana laboratorium akan memberikan pengalaman langsung untuk mengembangkan kompetensi peserta didik supaya mumpuni dalam menjelajahi dan menganalisis alam sekitar secara ilmiah, dan akan memberikan pengalaman untuk mengajukan dan menguji hipotesis dengan percobaan, merancang dan merakit instrumen percobaan, mengumpulkan, megolah, dan menafsirkan data, menyusun laporan dan mendiskusikan hasil percobaan dengan tertulis ataupun lisan.

Laboratorium yang baik harus memenuhi kelengkapan peralatan maupun memperhatikan fasilitas penunjang yang meliputi fasilitas umum maupun fasilitas khusus. Fasilitas umum berarti fasilitas yang digunakan semua pengguna laboratorium yang meliputi ventilasi, pencahayaan, air bersih, aliran listrik, dan lain-lain. Sedangkan fasilitas khusus adalah fasilitas yang digunakan oleh beberapa orang saja seperti meja siswa, meja guru, meja demonstrasi, lemari alat dan bahan, papan tulis, P3K, tabung 
pemadam kebakaran (Munarti \& Sutjihati, 2018). Ada beberapa faktor yang perlu menjadi perhatian apabila ingin membuat laboratorium IPA di SMP. Faktor pertama yaitu faktor limbah, faktor keamanan dan kenyamanan ruang, faktor ada tidaknya sumber listik dan terakhir adalah faktor sumber air (Meita, 2018). Ketiga faktor tersebut harus diperhatikan apabila ingin membuat laboratorium.

Standardisasi laboratorium IPA ini diatur didalam PERMENDIKNAS No. 24 tahun 2007 dimana ruang laboratorium IPA setidaknya bisa menampung kurang lebih 20 orang dengan luas minimum $48 \mathrm{~m}^{2}$ (sudah termasuk ruang penyimpanan dan ruang persiapan). Selain ukuran laboratorium, tata letak dan ruang laboratorium juga perlu diperhatikan. Menurut Wirjosoemarto, dkk, dalam Maulidiyah ruang laboratorium terdiri dari ruang utama dan ruang pelengkap (Maulidiyah et al., 2014). Ruang utama digunakan untuk kegiatan praktikum sedangkan ruang pelengkap seperti ruang penyimpanan dan ruang persiapan. Fasilitas peralatan laboratorium harus tersedia dalam jumlah standar yang disesuaikan dengan kebutuhan siswa agar proses kegiatan praktikum dapat berjalan dengan lancer sebagaimana mestinya.

Di MTs $X$ terdapat ruang laboratorium yang digunakan untuk melakukan kegiatan praktikum. Berdasarkan latar belakang tersebut peneliti tertarik untuk mengidentifikasi standardisasi laboratorium yang ada di MTs X. Kedua, peneliti termotivasi untuk menggali informasi apakah laboratorium yang terdapat disekolah tersebut bisa dikatakan layak atau tidak, difungsikan dengan baik atau tidak.

\section{METODE}

Jenis peneltian yang digunakan adalah peneitian deskriptif kualitatif. Menurut Sugiyono penelitian kualitatif merupakan penelitian yang menghasilkan data dan mengelolah data yang sifatnya deskriptif, seperti transkip wawancara, cacatan lapangan, gambar, foto, rekaman video, recorder, dan lain sebagainya (Alhamid \& Anufia, 1377). Penelitian kualitatif adalah penelitian yang tidak menggunakan teknik statistik dalam analisis datanya, tetapi cenderung menggunakan analisis untuk menafsirkan data yang diperoleh.

Metode kualitatif dengan pendekatan deskriptif adalah suatu cara penjabaran dan analisis data yang diperoleh dari informan. Peneliti mengambil metode kualitatif karena sesuai dengan judul penelitian ini yakni mengidentifikasi laboratorium IPA baik tata letak, tata ruang, dan ketersediaan alat dan bahan lab, peneliti ingin mengetahui tentang informasi mengenai laboratorium IPA secara mendalam dan menyeluruh. Penelitian ini dilakukan di MTs X yang terdapat di Desa Dawuhan, Kec. Mulbulsari, Kab. Jember, Provinsi Jawa Timur.

Sumber data yang dianalisis yakni berasal dari hasil wawancara. Adapun sumber data primer dalam peneltian ini adalah guru di MTs $X$ dan sumber data sekunder dalam penelitian ini adalah sumber yang diperoleh dari artikel jurnal nasional.

Teknik pengumpulan data menggunakan teknik wawancara bebas teipimpin, yang artinya pertanyaan yang dilontarkan kepada narasumber tidak terpaku pada lembar pedoman wawancara dan pertanyaan bisa dikembangkan sesuai dengan situasi dan kondisi yang ada di lapangan. Instrumen penelitian adalah alat yang membantu penelti untuk mengumpulkan data. instrumen yang digunakan dalam penelitian ini berupa lembar pedoman wawancara, perekam suara serta alat tulis yang dilakukan dengan guru IPA. 
Dalam penelitian pendekatan kualitatif, alat atau instrumen utama pengumpulan data tersebut adalah peneliti itu sendiri, karena peneltii mengumpulkan data dengan terjun langsung ke lapangan dan mengumpulkan data dengan bertanya, meminta, mendengar meminta dan mengambil data penelitian.

\section{HASIL DAN PEMBAHASAN}

\section{HASIL PENELITIAN}

Hasil wawancara bersama guru IPA di MTs X menunjukkan bahwa telah tersedia ruang laboratorium di sekolah tersebut. Berdasarkan hasil wawancara yang didapat diinformasikan bahwa kegiatan praktikum yang dilaksanakan di sekolah MTs X masih belum terlaksana dengan baik. Hal ini sesuai dengan apa yang dilontarkan oleh ibu Diana selaku guru IPA yang mengatakan bahwa kegiatan praktikum masih belum dilaksanakan secara rutin (jarang sekali).

"iya ada ruang laboratorium, tetapi kurang berfungsi. Karena pertama, siswanya masih sedikit, yang kedua peralatannya lengkap namun takut untuk pemakaiannya."

Peralatan yang terdapat di laboratorium MTs X pun bisa dikatakan lengkap, semua ada bahkan KIT fisika juga difasilitasi, hal ini sesuai dengan yang dikatakan Ibu Diana selaku guru IPA.

" peralatan yang ada di sana lengkap, memang sudah satu paket dengan peralatan fisika, teropong, lakmus ada disana, dan paling banyak itu peralatan fisika. Tetapi kalau bahan-bahan kimia kurang lengkap"

Kegiatan penjadwalan praktikum pun tidak terstruktur, masih belum dilaksanakan secara rutin, hal ini dikarenakan guru IPA menyesuaikan kegiatan praktikum dengan materi yang ada. Apabila dalam materi tersebut terdapat kegiatan praktikum, maka siswa diarahkan langsung ke ruang laboratorium.

" tidak ada jadwal, kalau mau praktikum itu langsung ke lab karena kendala siswa. Kalau ada materi tentang mikroskop ya kita ke ruang laboratorium, dan itu satu tahun sekali"

Karena kegiatan praktikum di sekolah MTs $X$ jarang dilakukan, maka peralatan yang sudah difasilitasi oleh sekolah kondisinya saat ini kurang baik, hal ini terjadi karena tidak adanya struktur pengelolaan laboratorium.

" tidak ada struktur kepala lab seperti itu, hanya guru saja yang mengelola tetapi jarang juga."

SOP yang diterapkan di laboratorium juga tidak ada, mengingat struktur organisasi laboratorium juga tidak ada. Jadi kegiatan praktikum dilaksanakan secara sederhana tanpa ada prosedur yang ditetapkan. Laboratorium seharusnya dikelola dengan baik, agar fasilitas yang sudah disediakan oleh sekolah bisa terjaga manfaatnya. Namun pasti ada beberapa faktor yang menyebabkan pengelolaan laboratorium tidak dioptimalkan, hal ini bisa terjadi karena faktor sumber daya pendidik yang kurang berpengalaman, kurangnya tenaga SDM di lembaga tersebut. Padahal kesan yang diciptakan peserta didik ketika melaksanakan praktikum sangat antusias, tertarik, senang. 


\section{PEMBAHASAN}

Berdasarkan hasil wawancara, dapat dikatakan bahwa kegiatan praktikum yang ada di sekolah MTs X kurang berfungsi secara maksimal, dimulai dari kegiatan praktikum, pengelolaan laboratorium, dan pemanfaatan fasilitas laboratorium. Ada beberapa faktor yang menyebabkan kurangnya kegiatan praktikum di MTs tersebut. Hal yang mendasar karena guru IPA yang mengajar di MTs X bukan berasal dari background bidang studi IPA, kemudian sulitnya mendapatkan perizinan dari pihak yayasan untuk menggunakan laboratorium karena takut alat-alat laboratorium menjadi rusak. Menurut Shinta kegiatan praktikum merupakan kegiatan yang berperan dalam meningkatkan keberhasilan proses belajar mengajar (Baeti, 2015). Kegiatan praktikum merupakan kegiatan yang penting dilakukan sebagai usaha guru untuk membekalkan ilmu dalam bentuk praktik terhadap teori yang sudah dipelajari. Terlebih lagi aktivitas praktikum dapat mendorong siswa untuk merekonstruksi pemahaman konseptualnya. Maka dari itu perlunya melaksanakan kegiatan praktikum bagi peserta didik agar dapat mengembangkan dan menerapkan keterampilan proses sains.

Standadisasi laboratorium IPA SMP/MTs diatur didalam PERMENDIKNAS No 24 tahun 2007 yang berkaitan tentang tata letak, tata ruang, dan fasilitas peralatan lainnya. Permendiknas No. 24 menyebutkan bahwa ruang laboratorium berfungsi sebagai sarana praktikum tempat dilaksanakannya pembelajaran IPA yang menggunakan alat-alat khusus. Berdasarkan PERMENDIKNAS No. 24 tahun 2007, laboratorium IPA SMP minimum dapat menampung kurang lebih 20 orang. Fasilitas yang seharusnya tersedia minimal terdapat cahaya yang memadai dalam ruangan untuk membaca dan melakukan observasi pada objek percobaan (Rahman \& Sumenep, 2017). Sarana yang terdapat di laboratorium setidaknya terdiri dari peralatan praktikum, media pendidikan dan perlengkapan lain seperti instalasi listrik, P3K, pemadam kebakaran, bak air bersih, tempat sampah dan jam dinding. Jenis-jenis perabot laboratorium IPA MTs X manurut narasumber lengkap. Hal ini berarti bisa dikatakan bahwa $85 \%$ perabotan laboratorium yang ada di MTs X sesuai dengan Peraturan Menteri No. 24 tahun 2007 yaitu terdiri dari kursi, meja demonstrasi, meja siswa, lemari alat, lemari bahan, dan bak cuci. Hanya beberapa kriteria yang kurang memenuhi yaitu, bahan kimia, poster IPA di dinding, alat pemadam kebakaran, model/peraga organ tubuh manusia, pemadam kebakaran, ruang persiapan, ruang penyimpanan dan lain sebagainya.

Tata letak laboratorium juga harus menjadi bahan pertimbangan karena hal ini berkaitan dengan kenyamanan, dan keamanan siswa dalam melaksanakan kegiatan praktikum. Letak laboratorium perlu benar-benar diperhatikan, beberapa faktor penting yang perlu diperhatikan ketika membangun ruang laboratorium adalah letak relatif dengan ruang-ruang lain dan pencahayaan (Sari, 2014). Ruang laboratorium sebaiknya diletakan ditempat yang strategis dengan lapangan atau pintu utama, hal ini dikarenakan apabila terjadi sesuatu hal terjadi dilaboratorium dapat segera diambil tindakan penyelamatan. Selain faktor keamanan dan keselamatan, faktor kenyamanan juga penting. Kenyamanan ruang laboratorium sangat diperlukan agar siswa dapat melaksanakan kegiatan praktikum dengan lancar dan tetap focus, tidak terganggu sesuatu hal. Laboratorium yang berada di MTs X terletak cukup strategis, dan letaknya jauh dari beberapa gangguan seperti kamar mandi, ruang drumband, dan kantin. Ruang laboratorium yang berada di sekolah tersebut bersebelahan dengan ruang kelas, dan penvahayaannya sangat baik. Pencahayaan laboratorium MTs $X$ sudah diperhatikan sebelum ruang ini dibangun, sebab pencahayaan ruangan menjadi faktor penting ketika melaksanakan kegiatan praktkum nantinya.

Letak laboratorium sebaiknya tidak ditempatkan bersebelahan dengan ruang kamar mandi, kantin dan ruang-ruang lain yang dapat menggangu konsentrasi siswa. 
Apabila ruang laboratorium diletakan bersebelahan dengan ruang kamar mandi, bisa saja ruang laboratorium menjadi lembab dan menyebabkan peralatan praktikum cepat rusak. Kantin sekolah yang ramai juga dapat menyebabkan terpecahnya konsentrasi siswa ketika kegiatan praktikum. Apabila ruang laboratorium berdekatan dengan kantin maka kegiatan pratikum tidak akan berjalan dengan lancar. Tidak hanya itu saja letak ruang laboratorium yang baik harus memiliki pencahayaan yang baik. Laboratorium sebaiknya arahnya terletak dari datangnya sinar matahari (Pujani \& Selamet, 2020). Cahaya matahari sangat diperlukan untuk menerangi ruangan, sebab kegiatan praktikum terkadang membutuhkan pengamatan yang memerlukan pencahayaan lebih. Tidak hanya itu saja beberapa penyimpanan peralatan juga membutuhkan penyinaran matahari agar peralatan tidak lembab dan rusak.

Selain tata letak lokasi, perlu diperhatikan pula tata letak ruangan. Ruang laboratorium umumnya terdiri dari ruang praktik, ruang penyimpanan dan ruang persiapan. Desain ruangan laboratorium dengan minimum mencakup $2,4 \mathrm{~m}^{2}$ per peserta didik dan menampung minimum 20 orang di dalamnya, dengan kisaran luas $48 \mathrm{~m}^{2}$ (Rahman \& Sumenep, 2017). Dan ukuran ruang utama lebih besar dari ruang penyimpanan, contoh misalnya besar ruang laboratorium sebesar $100 \mathrm{~m}^{2}$, maka 70-80 $\mathrm{m}^{2}$ ditempati ruang utama dan sisahnya untuk ruang penyimpanan. Ruangan laboratorium yang berada di MTs X besarnya cukup untuk menampung jumlah siswa yang ada, tidak terlalu besar dan tidak terlalu kecil. Didalam ruang laboratorium IPA tersebut bisa dikatakan kurang sesuai dengan kriteria tata ruang laboratorium sebab lemari bahan dan alat dijadikan satu dengan ruang praktikum, jika ditinjau dari standarisasi yang terdapat di dalam Permendiknas No. 24 tahun 2007 bahwa ruang laboratorium terdiri dari ruang praktikum, ruang penyimpanan dan ruang persiapan.

Ruang laboratorium yang berada di MTs X hanya ada satu ruang saja yang mencakup meja demontrasi, meja praktikum, kursi, papan tulis, lemari alat, lemari bahan. Ventilasi dan pencahayaannya yang terdapat di ruang laboratorium kondisinya baik, pencahanyaannya cukup untuk melakukan kegiatan membaca buku ataupun mengamati objek. Ruang laboratorium yang ada di MTs $X$ terletak di samping ruang kelas dan letaknya stategis, tidak lembab, dan aman dari gangguan lapangan sepak bola.

Dilihat dari kurangnya kegiatan praktikum dan masih belum terdapat pengelolah laboratorium, maka dapat diindikasikan bahwa beberapa alat dan bahan yang berada di laboratorium MTs $X$ ada yang dalam keadaan rusak. Hal ini berkaitan dengan tidak adanya kegiatan pengelolaan laboratorium, padahal kegiatan pengelolaan laboratorium sangat penting dilakukan, agar inventaris alat dan bahan dapat terjaga dengan baik. Struktur pengelolaan yang ada di laboratorium MTs $X$ juga tidak ada, karena laboratorium tidak dipegang oleh guru IPA melainkan dipegang oleh pemilik yayasan. Sehinga laboratoium hanya sebagai fasilitas yang ada namun tidak dioptimalkan dengan baik. Pengelolaan laboratorium merupakan kegiatan pengelola dalam mendayagunakan perlengkapan laboratorium secara efektif dan efisien. Pengelolaan laboratorium berkaitan dengan pengelolaan dan penggunaan fasililtas laboratorium.

Pengelolaan laboratorium tidak dapat dipisahkan dari kegiatan laboratorium karena pelaksanaan praktikum pastinya membutuhkan alat dan bahan yang sebelumnya diperiksa ketersediaannya di dalam ruang penyimpanan. Apabila alat dan bahan yang tersedia sudah rusak maka kegiatan praktikum tidak dapat berjalan, dan hal ini berdampak pada kurangnya pengalaman siswa dalam mengasah keterampilan proses sains. Pengelolahan laboratorium dapat terwujud apabila dilakukan dengan langkahlangkah sistematis. (Marpanaji, 2017) mengatakan langkah-langkah pengelolaan laboratorium sekolah meliputi kegiatan-kegiatan perencanaan, pengorganisasian, pemeliharan, dan pengawasan. Dengan adanya pengelola laboratorium maka sistem 
pengelolaan alat maupun bahan dapat tertata sesuai dengan SOP yang ada. Disisi lain pengelolaan laboratorium juga memiliki peranan penting sebagai penunjang keberhasilan kegiatan lab. Narasumber juga berharap agar laboratorium yang ada bisa difungsikan secara optimal, sebab beberapa peralatan dan bahan yang tersedia sudah cukup lengkap, namun karena kurang mendapatkan izin menggunakan laboratorium oleh pemilik yayasan jadi kegiatan praktikum jarang dilaksanakan.

\section{KESIMPULAN}

Kegiatan praktikum merupakan sesuatu hal yang tidak dapat dipisahkan dari pelajaran IPA. Jika membahas materi IPA pasti ada kaitannya dengan kegiatan praktik. Karena beberapa materi IPA merupakan materi abstrak dan perlu dibuktikan agar dapat menambah pemahaman siswa.

Berdasarkan hasil wawancara bersama narasumber dapat disimpulkan bahwa ruang laboratorium yang berada di MTs $X$ tidak difungsikan secara maksimal, karena beberapa faktor yakni karena guru IPA bukan berasal dari background bidang studi IPA, kemudian sulitnya mendapatkan perizinan dari pihak yayasan untuk menggunakan laboratorium. Laboratorium IPA di MTs tersebut kurang dioptimalkan secara baik, hal ini dibuktikan dengan tidak adanya struktur organisasi yang terdapat di laboratorium serta tidak ada SOP yang diterapkan.

Tata letak dan ruang laboratorium yang berada di MTs $X$ bisa dikatakan kurang sesuai. Untuk lokasi laboratorium itu sendiri terletak di antara ruang kelas dan jauh dari sumber gangguan. Sedangkan letak ruang laboratorium hanya terdapat ruang utama saja, ruang penyimpanan dijadikan satu dengan ruang utama. Ruang utama tersebut mencakup meja demontrasi, meja praktikum, kursi, papan tulis, lemari alat, lemari bahan dan perabotan lain. $85 \%$ perabotan laboratorium yang ada di MTs $X$ sesuai dengan Peraturan Menteri No. 24 tahun 2007 yaitu terdiri dari kursi, meja demonstrasi, meja siswa, lemari alat, lemari bahan, dan bak cuci. Hanya beberapa kriteria yang kurang memenuhi yaitu, bahan kimia, poster IPA di dinding, alat pemadam kebakaran, model/peraga organ tubuh manusia, pemadam kebakaran, ruang persiapan, ruang penyimpanan dan lain sebagainya.

\section{UCAPAN TERIMAKASIH}

Penulis mengucapkan terimakasih sebanyak-banyaknya kepada sekolah MTs X yang bersedia menjadi objek penelitian kami sehingga kami dapat menghasilkan sebuah karya yang dapat menjadi pertimbangan Pemerintah dan pihak Swasta untuk membantu mengoptimalkan kualitas dan kuantitas laboratorium disemua sekolah sebagaimana standar yang ditetapkan, dan terimakasih kepada guru IPA yang telah memberikan waktunya untuk menjadi informan pada penelitian ini.

\section{DAFTAR PUSTAKA}

Adilah, M., Setiadi, A. E., \& Kahar, A. P. (2021). ANALISIS STANDARISASI LABORATORIUM BIOLOGI SEKOLAH MENENGAH ATAS (SMA) DI KOTA PONTIANAK (The Analysis of Standardization of Biology Laboratory at Senior High School in 
Pontianak). JURNAL ILMIAH DIDAKTIKA: Media I/miah Pendidikan Dan Pengajaran, 21(2), 195. https://doi.org/10.22373/jid.v21i2.5995

Alhamid, T., \& Anufia, B. (1377). INSTRUMEN PENGUMPULAN DATA. 68-70.

Baeti, S. N. (2015). Pembelajaran Berbasis Praktikum Bervisi Sets Untuk Meningkatkan Keterampilan Laboratorium Dan Penguasaan Kompetensi. Jurnal Inovasi Pendidikan Kimia, 8(1), 1260-1270.

Eka Novita Sari, R. S. B. A. H. (2014). Persepsi Siswa tentang Kegiatan Praktikum Biologi di Laboratorium SMA Negeri Se-Kota Jambi. Jurnal Sainmatika, 8(1), 49-59.

Marpanaji, E. D. I. A. A. B. . P. U. B. D. F. B. E. ; N. W. S. W. (2017). Optimalisasi Pengelolaan Laboratorium (Laboratory Management) untuk Meningkatkan Kinerja Pengelola dan Penggunaan Laboratorium Sekolah Menengah Kejuruan. Ppm, 11.

Maulidiyah, R., Ardi, D., Si, M., Sari, L. Y., \& Pd, M. (2014). Negeri Se- Kabupaten Pasaman Barat.

Meita, N. M. (2018). Standardisasi Laboratorium IPA SMPN 3 Sumenep. PENDIPA Journal of Science Education, 2(2), 227-234. https://doi.org/10.33369/pendipa.2.3.227-234

Munarti, M., \& Sutjihati, S. (2018). Standar Sarana Prasarana Laboratorium Ipa Sekolah Menengah Atas Di Wilayah Bogor. Pedagonal : Jurnal Ilmiah Pendidikan, 2(1), 5662. https://doi.org/10.33751/pedagog.v2i1.743

Murti, S., Muhibbuddin, \& Nurmaliah, C. (2014). Penerapan Pembelajaran Berbasis Praktikum Untuk Peningkatkan Kemampuan Kognitif Dan Psikomotorik Pada Perkuliahan Anatomi Tumbuhan. Jurnal Biologi Edukasi, 6(1), 1-8.

Pujani, N. M., \& Selamet, K. (2020). Pengelolaan Laboratorium Ilmu Pengetahuan Alam ( Ipa ) Smp Negeri 2 Singaraja. Jurnal Pendidikan Dan Pembelajaran Sains Indonesia (JPPSI), 3(3), 118-129.

Rahman, M. S., \& Sumenep, S. (2017). Kajian Standarisasi Sarana Prasarana Laboratorium Di Smpn 4 Sumenep. Jurnal Lensa (Lentera Sains): Jurnal Pendidikan IPA, 7(24), 1-12.

Subiantoro, A. W. (2014). Pentingnya Praktikum. Fmipa Uny, ipa, 1-11. http://staffnew.uny.ac.id/upload/132309690/pengabdian/PPM_PENTINGNYA+PRAKT IKUM.pdf 